Single-Phase Heat Transfer and Pressure Drop

Characteristics of an Integral-Spine-Fin Within an Annulus

Mark A. Kedzierski

Min Soo Kim

Building and Fire Research Laboratory

Gaithersburg, Maryland 20899

United States Department of Commerce

Technology Administration

National Institute of Standards and Technology

$-Q C$

100

.456

N0. 5454

1994 

NISTIR 5454

\section{Single-Phase Heat Transfer and Pressure Drop Characteristics of an Integral-Spine-Fin Within an Annulus}

Mark A. Kedzierski

Min Soo Kim

Building Environment Division

Building \& Fire Research Laboratory

June 1994

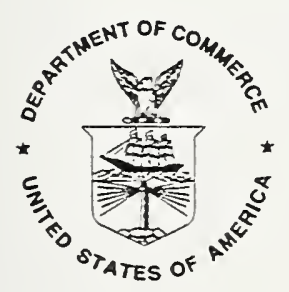

U.S. Department of Commerce

Ronald H. Brown. Secretary

Technology Administration

Mary L. Good, Under Secretary for Technology

National Institute of Standards and Technology

Arati Prabhakar, Director
Prepared for:

U.S. Department of Energy

Esher Kweller

Office of Building Technology

Building Equipment Division

Conservation and Renewable Energy

Washington, DC 20585 



\section{TABLE OF CONTENTS}

ABSTRACT $\ldots \ldots \ldots \ldots \ldots \ldots \ldots \ldots \ldots \ldots \ldots \ldots \ldots \ldots$

NOMENCLATURE $\ldots \ldots \ldots \ldots \ldots \ldots \ldots \ldots \ldots \ldots \ldots \ldots \ldots$

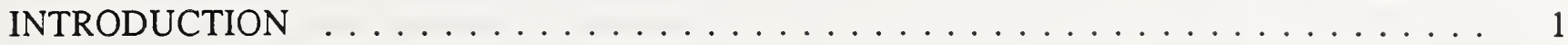

APPARATUS AND FLOW CONDITION $\ldots \ldots \ldots \ldots \ldots \ldots \ldots$

FANNING FRICTION FACTOR $\ldots \ldots \ldots \ldots \ldots \ldots \ldots \ldots \ldots$

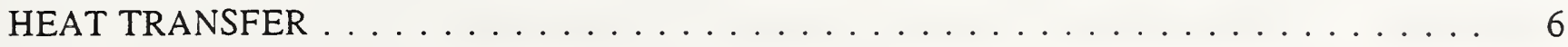

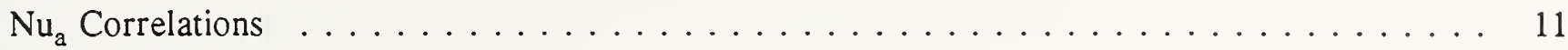

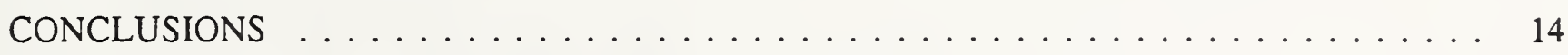

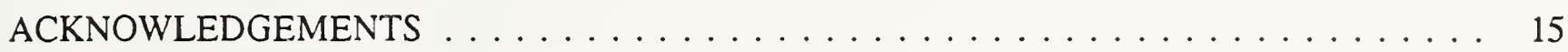

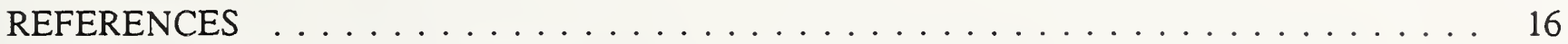




\begin{abstract}
The laminar, single-phase heat transfer and friction characteristics of a porcupine-like surface (integralspine-fin) within an annulus are presented. The heat-transfer coefficient was determined using a modified version of the Wilson Plot method on a $3 \mathrm{~m}$ test section. Three fluids were investigated: (1) water, (2) $34 \%$ ethylene glycol/ water mixture, and (3) $40 \%$ ethylene glycol/water mixture. These fluids produced a significant variation in the Prandtl number so that its exponential dependence could be determined. The annulus Reynolds numbers were varied from 100 to 1400 to obtain the Reynolds number exponent. An empirical correlation for the Nusselt number that accounts for the development of the thermal boundary layer is presented. An empirical correlation for the fanning friction factor is also provided. It is shown that the spines enhance the heat transfer through additional surface area and fluid mixing.
\end{abstract}

Keywords: annulus, enhanced heat transfer, spine-fin, friction, water, ethylene glycol 


\section{NOMENCLATURE}

\section{English Symbols}

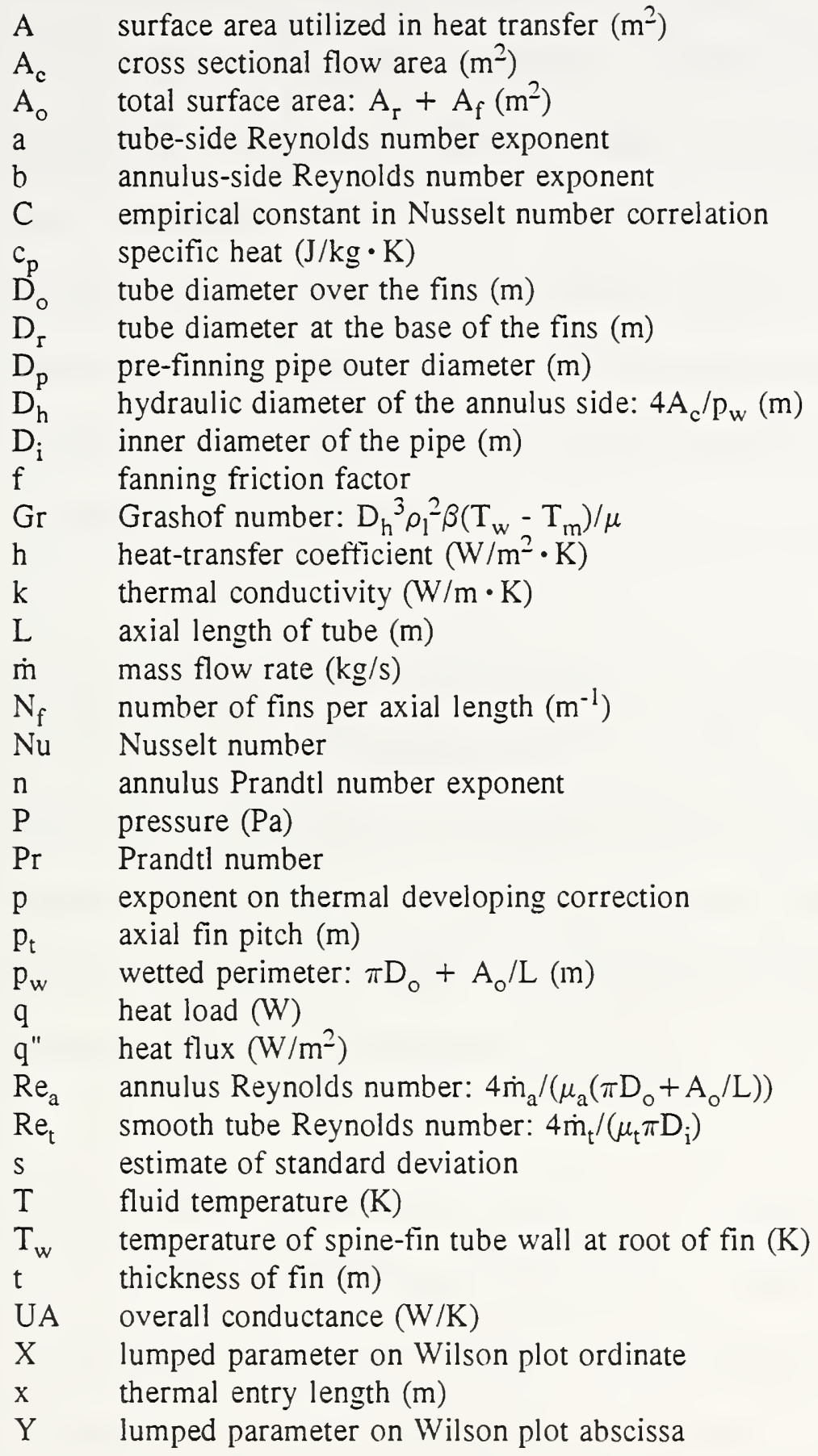

Greek symbols

$\beta \quad$ coefficient of volumetric thermal expansion $\left(\mathrm{K}^{-1}\right)$

$\Delta \mathrm{P} \quad$ pressure drop $(\mathrm{Pa})$

$\Delta \mathrm{T}_{\mathrm{lm}} \quad$ log-mean temperature difference $(\mathrm{K})$

$\Delta \mathrm{x} \quad$ distance between pressure taps (m)

$\eta \quad$ surface efficiency 


$$
\begin{array}{ll}
\eta_{\mathrm{f}} & \text { fin efficiency } \\
\Theta & \left(\mathrm{T}_{\mathrm{w}}-\mathrm{T}_{\mathrm{i}}\right) /\left(\mathrm{T}_{\mathrm{w}}-\mathrm{T}_{\mathrm{m}}\right) \\
\mu & \text { dynamic viscosity }(\mathrm{kg} / \mathrm{m} \cdot \mathrm{s}) \\
\rho & \text { density }\left(\mathrm{kg} / \mathrm{m}^{3}\right)
\end{array}
$$

\section{Subscripts}

$\begin{array}{ll}\text { a } & \text { annulus-side fluid } \\ \text { cu } & \text { copper } \\ \text { f } & \text { fin } \\ \text { i } & \text { inlet } \\ \text { l } & \text { liquid } \\ \text { m } & \text { mean, bulk } \\ \text { r } & \text { root } \\ \text { t } & \text { tube-side fluid }\end{array}$




\section{INTRODUCTION}

This paper presents empirical correlations for the single-phase Nusselt number and fanning friction factor for an integral-spine-fin within an annulus. A modified Wilson Plot was used to derive the Nusselt numbers from overall conductance measurements. The friction factors were calculated from pressure drop measurements. The test fluids -- water, $34 \%$ ethylene glycol/water mixture, and a $40 \%$ ethylene glycol/water mixture -- were chosen to provide a significant variation in the Prandtl Number (4 to 22 ). In this way, the exponential dependence of the Prandtl number on the heat transfer was experimentally determined. For an analogous reason, the annulus Reynolds numbers were varied from 100 to 1400 . Average heat fluxes to the test section ranged from 13.5 to $54 \mathrm{~kW} / \mathrm{m}^{2}$.

Very little friction and heat transfer data exist for the integral-spine-fin. Most studies have been done for tubes in cross flow (Holtzapple and Carranza (1990)). The work of Hobson and Weber (1954) is, to the authors' knowledge, the only reported work to use the integral-spine-fin within an annulus. However, the fin-tips in their study did not touch the outer shell which allowed the fluid to bypass the fins. Also, the flow was turbulent. In contrast, all of the annulus-side Reynolds numbers in the present study are laminar and the fins touch the outer shell.

Both radial and axial cross sectional schematics of the integral-spine-fin tube are given in Figure 1. The tube has approximately 8189 fins per meter $\left(N_{f}\right)$ and an axial fin pitch $\left(p_{t}\right)$ of $3.175 \mathrm{~mm}$. The diameter of the tube over the fins $\left(D_{0}\right)$ is $26.8 \mathrm{~mm}$. The tube diameter at the base of the fins $\left(D_{r}\right)$ is $11.72 \mathrm{~mm}$. The root surface area per unit length -- $A_{r} / L=32.76 \mathrm{~mm}--$ was calculated from: $\pi D_{r}\left(1-t_{r} / p_{t}\right)$, where an average $t_{r}$ of $0.35 \mathrm{~mm}$ was used. The hydraulic diameter of the annulus side with the fin-tips snugly touching the outer tube wall is $4.59 \mathrm{~mm}$. The inner diameter of the pipe $\left(\mathrm{D}_{\mathrm{i}}\right)$ is $9.53 \mathrm{~mm}$. The fins are not quite $90^{\circ}$ with respect to the tube axis. However, several tests were conducted which showed that the flow direction with respect to the fin angle does not have a measurable effect on the heat transfer for 
the present flow conditions.

The integral-spine-fins are formed by lifting the metal from the outer wall of a smooth copper pipe. In this study, the pre-finning pipe outer diameter $\left(D_{p}\right)$ was $13.7 \mathrm{~mm}$. For a given outer tube, finning of the copper pipe results in 6.48 times the surface area and the same cross sectional $\left(A_{c}\right)$ flow area as the prefinning geometry. As shown in Figure 2, the spines of our tube resembled a copper tadpole with its twisted tail integrally attached to the root surface of the tube. The spines of different tubes do not necessarily resemble tadpoles. The spine fin cross section may vary depending on the number of spines per turn, the base material, and the condition of the tool used to produce them (Vandersip, 1993). The tail cross section of the spine in this study was nearly triangular. The cross section of the spine head or fin-tip was trapezoidal. The surface area of one fin was estimated from the measurements shown in Figure 2 to be approximately $3 \times 10^{-5} \mathrm{~m}$. The total outside surface area per unit length -- $A_{o} / L=A_{r} / L$ $+\mathrm{N}_{\mathrm{f}} \mathrm{A}_{\mathrm{f}}$-- was estimated to be $0.279 \mathrm{~m}$. The volume of metal in all of the spines calculated using Figure 2 and that calculated from the reduction in the pipe wall after finning agreed within $1 \%$.

If measurements of the spine's dimensions are unavailable, the total surface area (root and fin surface area) of other spine fin geometries may be estimated from:

$$
\frac{A_{0}}{L}=\pi D_{I}-\frac{\pi D_{I} t_{I}}{D_{t}}+\left(0.4 m m+\frac{\pi\left(D_{D}^{2}-D_{I}^{2}\right)}{0.4 m m N_{f}\left(D_{0}-D_{I}\right)}\right)\left(D_{0}-D_{I}\right) N_{f}
$$

The above equation approximates the fin cross section as rectangular and assumes that one of the sides is $0.4 \mathrm{~mm}$ wide. The width of the other spine side was obtained by setting the volume of metal lifted from the tube to form one fin equal to the volume of a rectangular spine. 


\section{APPARATUS AND FLOW CONDITION}

Figure 3 shows a schematic of the test rig which was used to simultaneously obtain heat transfer and friction data. A cross section of the straight $3 \mathrm{~m}$ test section is shown in Fig 3. The test fluid was pumped through the annulus. Tap water was pumped through the smooth inner tube at a steady flow rate of approximately $0.18 \mathrm{~kg} / \mathrm{s}$ to ensure large turbulent Reynolds numbers. The mass flow rates were measured with a coriolis flow meter having an estimated uncertainty of $0.001 \mathrm{~kg} / \mathrm{s}$ for a $99.7 \%$ confidence interval. (All uncertainties are for a $99.7 \%$ confidence interval unless otherwise stated.) The temperature difference $(\Delta T)$ for each fluid stream was measured with a ten element thermopile to within $0.01 \mathrm{~K}$. Mixers were used before the thermopiles to ensure the measurement of bulk temperatures. The condenser and evaporator of a refrigeration system (shown as heat exchangers in Figure 3) were used to supply and remove, respectively, the heat of the two fluid streams. The condenser and evaporator streams were switched to achieve both annulus-side heating and cooling conditions. Two differential pressure transducers, accurate to within $0.26 \mathrm{kPa}$, were used to measure the pressure drop of each stream. Table 1 shows the estimated percent uncertainty for various measurements. The uncertainty estimates given in Table 1 are the root-sum-square of the component uncertainties.

As shown in Figure 3, the pressure taps were located far enough from the tube bends to ensure that the pressure drop measurements were for fully developed hydraulic flow. Mattingly and Yeh (1991) have presented a method for estimating the decay of turbulent swirl induced by a $90^{\circ}$ bend. The swirl effect increases for increasing Reynolds Number. Twenty-four tube diameters are required for swirl to dissipate to $1 \%$ of its greatest value for $\mathrm{Re}_{\mathrm{t}}=40,000$ (our largest $\mathrm{Re}_{\mathrm{t}}$ ). On the smooth tube side, we conservatively used 32 diameters so that the pressure drop measurements would not be affected by the $90^{\circ}$ bend. On the annulus side, the effect of hydraulically developing flow and $90^{\circ}$ bends on the pressure drop measurements should be minimal since the taps were located $66 \mathrm{D}_{\mathrm{h}}$ from the bends, and mixing induced by the fins should quickly establish the flow. 
Ideally, the tube-side heat-transfer coefficient should be nearly constant along the tube length for accurate Wilson plot results. A nearly constant heat-transfer coefficient can be achieved if the flow is thermally developed. Deissler (1955) shows that the thermal entry length is approximately 3 tube diameters for turbulent flow inside a smooth circular tube. If the solution given by Deissler (1955) is integrated over the entrance region, the average tube-side heat-transfer coefficient for the present test section would be less than $1 \%$ greater than the constant, thermally developed value. Consequently, the tube-side entrance region for the present test rig should have a negligible effect on the accuracy of the Wilson Plot method.

Conversely, the thermal entry length $(x)$ on the annulus side is significant for most of the 171 heat transfer data points. It was estimated from an expression -- $\mathrm{x}=0.05 \mathrm{D}_{\mathrm{h}} \operatorname{RePr}-$ given by Kays and Crawford (1980) to be from $16 \%$ to $66 \%$ (38\%, on average) of the $3 \mathrm{~m}$ test section. Consequently, this paper empirically correlates thermally developing flow data. Considering that laminar flow exists for many liquid heat exchangers in ground source heat pumps and other equipment, a predictive correlation should include a correction for thermally developing flow. Although the local heat transfer varies along the entry length, the accuracy of the Wilson plot method is not compromised since the variation is accounted for by using an appropriate expression in the correlation for the average Nusselt number.

\section{FANNING FRICTION FACTOR}

Mass flow rate $(\dot{m})$ measurements and differential pressure $(\Delta \mathrm{p})$ measurements across a $2.47 \mathrm{~m}$ length of the annulus $\left(\Delta \mathrm{x}_{\mathrm{a}}\right)$ and a $3.46 \mathrm{~m}$ length of the inner tube $\left(\Delta \mathrm{x}_{\mathrm{t}}\right)$ were used to calculate the fanning friction factors for the respective flows. The fanning friction factor for the smooth tube side was calculated from:

$$
f_{t}=\frac{-\rho_{I_{t}} \Delta P_{t} \pi^{2} D_{i}^{5}}{32 \dot{m}_{t}^{2} \Delta x_{t}}
$$


The uncertainty of $f_{t}$ is estimated to be $1.5 \%$ of $f_{t}$.

The annulus-side fanning friction factor was calculated from:

$$
f_{a}=\frac{2 \rho_{I_{a}} A_{c}^{3} \Delta P_{a}}{\Delta x_{a} \dot{m}_{a}^{2}\left(\pi D_{0}+\frac{A_{0}}{L}\right)}
$$

The uncertainty of $f_{a}$ is estimated to be $0.003 \mathrm{~kg} / \mathrm{s}$. That is, the uncertainty is $10 \%$ and $2 \%$ of $f_{a}$ for the lowest flow rate $(0.03 \mathrm{~kg} / \mathrm{s})$ and the highest flow rate $(0.15 \mathrm{~kg} / \mathrm{s})$, respectively.

Two-hundred-and-eighty-one data points were used to fit the measured friction factors to the measured Reynolds number. The smooth-tube-side fanning friction factor correlation developed from the present heating and cooling data is:

$$
f_{t}=\left(1.25 \ln \left(R e_{t}\right)-0.235\right)^{-2}
$$

The standard deviation of the correlated $f_{t}$ from the measured value was estimated to be $1.9 \%$ of the measured value.

Figure 4 compares the present measurements of $f_{t}$ to the friction factor correlation given by Filonenko (1954) for turbulent flow within a smooth tube:

$$
f_{t}=\left(1.58 \ln \left(R e_{t}\right)-3.28\right)^{-2}
$$

The Filonenko (1954) equation agrees within approximately $10 \%$ of the measured tube-side friction factor. The heating and cooling friction factors nearly coincide for Reynolds numbers above 20,000 . 
The friction factors for cooling are marginally above those for heating for Reynolds numbers below 10,000 ; the difference is within the uncertainty of the measurement for low mass flow rates. The agreement between the present measurements and the Filonenko (1954) equation indicates that the method used to measure the friction factor is reliable.

The measured annulus-side fanning friction factor was correlated to the measured annulus Reynolds number. The resulting annulus-side fanning friction factor correlation for the spined annulus with the spines touching the outer wall is:

$$
f_{a}=\left(0.163 \ln \left(R e_{a}\right)+0.238\right)^{-2}
$$

Figure 5 compares the measured data to the above correlation. The estimated standard deviation between the measurements and the correlation was $2.4 \%$ of the measurement. No measurable difference between heating and cooling data exists.

The friction correlation given by Hobson (1954) is approximately $60 \%$ below the data presented here. This supports Hobson's (1954) conjecture that his relationship for spines in contact with the outer wall would not be satisfactory. Apparently, a significantly lower friction factor results when the flow bypasses the fins. The measured friction factor for the integral-spine-fin-annulus is 15 times the laminar, smooth tube friction provided by Davis (1943). This is expected since the profile drag on the fins contributes much more to the pressure drop than does the skin friction on the tube walls.

\section{HEAT TRANSFER}

The heat-transfer coefficient for the integral-spine-fin-annulus $\left(\mathrm{h}_{\mathrm{a}}\right)$ was derived from the measured overallconductance (UA) of the heat exchanger using a Wilson plot technique similar to that given by Briggs 
and Young (1969). The methodology of the present Wilson plot differs from that of Briggs and Young (1969) in two ways: (1) the Prandtl number exponent on the annulus side is taken as unknown and, (2) an additional term is included to account for thermally developing flow of the annulus side.

The governing equation of the Wilson plot technique is the overall conductance equation. The overall conductance (UA) can be represented by a sum of the individual thermal resistances:

$$
\frac{1}{U A}=\frac{\Delta T_{1 m}}{q}=\frac{1}{h_{t} A_{t}}+\frac{\ln \left(\frac{D_{r}}{D_{i}}\right)}{2 \pi L k_{c u}}+\frac{1}{\eta h_{a} A_{a}}
$$

The log-mean temperature difference $\left(\Delta \mathrm{T}_{\mathrm{lm}}\right)$ is calculated from the measured temperature drop of each fluid stream. The heat load $(\mathrm{q})$ of the heat exchanger is calculated from the measured mass flow rate and temperatures; the average of the two fluid streams is used. The $h_{t}$ is the heat-transfer coefficient of the inner smooth tube and is based on the tube-side area $A_{t}\left(\pi D_{i} L\right)$. The next to the last term is the thermal resistance of the tube wall between the fluids. The only parameters in Eq. (7) that cannot be directly measured or calculated are the tube-side and annulus-side heat-transfer coefficients, $h_{t}$ and $h_{a}$.

The basic strategy of the Wilson plot (1915) is to substitute functional forms with unknown constants for the tube-side and annulus-side thermal resistances into the overall conductance equation and linearize it so that the unknown constants can be obtained from the slope and the intercept of a linear regression. The functional form of the tube-side Nusselt $\left(\mathrm{Nu}_{\mathrm{t}}\right)$ number was assumed to be:

$$
N u_{t}=\frac{h_{t} D_{i}}{k_{t}}=C_{t} \operatorname{Re}_{t}^{a} \operatorname{Pr}_{t}^{\frac{1}{3}}\left(\frac{\mu}{\mu_{w}}\right)_{t}^{0.14}
$$

The last parameter, the ratio of the bulk and wall liquid viscosities to the 0.14 power, is the Sieder-Tate 
(1936) correction to account for radial property variations. The liquid Reynolds number $\left(\operatorname{Re}_{\mathrm{t}}=\right.$ $\left.4 \dot{\mathrm{m}}_{\mathrm{t}} /\left(\mu_{\mathrm{t}} \pi \mathrm{D}_{\mathrm{i}}\right)\right)$ and the liquid Prandtl number $\left(\mathrm{Pr}_{\mathrm{t}}\right)$ are evaluated at the bulk temperature. The unknown constant $C_{t}$ is determined via the Wilson plot. Conversely, the value of the Reynolds number exponent (a) is specified with a certain degree of uncertainty.

The dubiousness of the tube-side Reynolds number exponent (a) can be a serious limitation to the Wilson plot method (Shah, 1990). Shah (1985) notes that the exponent (a) may vary from 0.7 to 0.9 depending on the Reynolds and Prandtl numbers. To remedy this, Webb (1993) suggested that the exponent (a) be determined from a best fit of Eq. (8) to a modified version of the Petukhov-Popov equation (Gnielinski, 1976) -- valid in the range $2300<\operatorname{Re}<10^{4}-$ for the $\mathrm{Pr}$ and $\mathrm{Re}$ range of our data. It is appropriate to use the Petukhov-Popov equation to determine the exponent since it predicts the single-phase Nusselt number for fully developed flow within a smooth tube to an uncertainty of $\pm 6 \%$ for $0.5<\operatorname{Pr}<200$. A Reynolds number exponent of 0.897 and $\mathrm{C}_{\mathrm{l}}$ of 0.0122 resulted from this fit.

The methodology of the Wilson plot dictates that one must assume a functional form for the annulus-side Nusselt number. The smooth annulus Nusselt number is a constant for fully developed laminar flow (Jakob and Rees, 1941). However, a substantial proportion of the total test section length was in thermally developing flow for most of the test data. Consequently, a functional form is necessary to account for thermally developing flow. Kays and Crawford (1980) provide such an expression for a circular tube of length $\mathrm{L}$ and inner diameter $\mathrm{D}_{\mathrm{i}}$ with a constant wall temperature $\left(\mathrm{T}_{\mathrm{w}}\right)$ :

$$
N u_{m}=\frac{\operatorname{RePr} \ln \left(\frac{T_{w}-T_{i}}{T_{w}-T_{m}}\right)}{4 \frac{L}{D_{i}}}
$$

It is speculated that Eq. (9) contains the primary parameters which govern thermally developing laminar 
flow in a spine-fin-annulus. The product of $\operatorname{Re}, \operatorname{Pr}$, and $D_{i}$ is also found in the expression for the local Nusselt number. The logarithmic factor $(\ln \theta)$ results from the integration of the local developing Nusselt number over the entry length. The resulting average Nusselt number in the thermally developing region depends on the entering fluid temperature $\left(\mathrm{T}_{\mathrm{i}}\right)$, the wall temperature $\left(\mathrm{T}_{\mathrm{w}}\right)$, and the bulk temperature of the fluid $\left(T_{m}\right)$. Average values of $T_{w}$ and $T_{m}$ were used since the wall temperature was not constant.

Making an analogy with Eq. (9), the following form was chosen for the annulus-side Nusselt number $\left(\mathrm{Nu}_{\mathrm{a}}\right)$ :

$$
\mathrm{Nu}_{a}=\frac{h_{a} D_{h_{a}}}{k_{a}}=C_{a} \operatorname{Re}_{a}^{b} \operatorname{Pr}_{a}^{n}\left(\frac{D_{h}}{L} \ln \frac{T_{w}-T_{i}}{T_{w}-T_{m}}\right)_{a}^{p}
$$

The above form produced a Wilson plot with the best fit of all forms attempted. A best fit was defined as one that produced the smallest percent standard deviation $\left(\% \mathrm{~s}_{\mathrm{Y}_{1}}\right.$ and $\left.\% \mathrm{~s}_{\mathrm{Y} 2}\right)$ from the Wilson plot fit with a value of $C_{t}$ close to 0.0122 . Table 2 shows the effect of the inclusion of various combinations of the Grashof number $(\mathrm{Gr})$, the Sieder-Tate (1936) correction, and the thermally developing correction $\left(D_{h}{ }^{p} \ln \Theta^{P} / L^{p}\right)$ proposed here. Only the $D_{h}{ }^{P} \ln \Theta^{P} / L^{p}$ term was included in the annulus-side correlation since its inclusion without the other corrections produced the best fit. The exclusion of the Gr and the property correction suggests that natural convection and large radial temperature gradients are not present. This is consistent with the values of $\mathrm{Gr} / \mathrm{Re}^{2}<<1$ (typically 0.015 for our tests), and Prandtl numbers below 25. The Sieder-Tate (1936) correction is probably not necessary since for the given $\operatorname{Pr}$ and $\operatorname{Re}$ ranges the fins radially mix the flow. The thermally developing term was a 4 to $20 \%$ correction of $\mathrm{Nu}_{\mathrm{a}}$ for our data.

Substituting the tube-side and the annulus-side Nusselt number forms into the overall conductance 
equation and rearranging into a form that is convenient for the linear solution of $\mathrm{C}_{\mathrm{t}}$ and $\mathrm{C}_{\mathrm{a}}$ gives:

$$
\begin{aligned}
\frac{\eta k_{a}}{D_{h_{a}}} \operatorname{Re}_{a}^{b} \operatorname{Pr}_{a}^{n} A_{0}\left(\frac{D_{h}}{L} \ln \theta\right)^{p}\left(\frac{\Delta T_{1 m}}{q}-\frac{\ln \frac{r_{I}}{r_{i}}}{2 \pi L k_{c u}}\right)= \\
\frac{1}{C_{t}} \frac{\frac{\eta k_{a}}{D_{h_{a}}} \operatorname{Re}_{a}^{b} \operatorname{Pr}_{a}^{{ }^{n}} A_{o}\left(\frac{D_{h}}{L} \ln \theta\right)^{p}}{\frac{k_{t}}{D_{i}} \operatorname{Re}_{t}{ }^{897} \operatorname{Pr}_{t}^{\frac{1}{3}} A_{i}\left(\frac{\mu}{\mu_{w}}\right)_{t}^{0.14}}+\frac{1}{C_{a}}
\end{aligned}
$$

Figure 6 shows a plot of Eq. (11) where the ordinate $\left(\mathrm{Y}_{1}\right)$ is the first term, and the abscissa $\left(\mathrm{X}_{1}\right)$ is the second term divided by $C_{t}{ }^{-1}$. The constants $C_{t}$ and $C_{a}$ are the inverses of the slope and intercept of Figure 6 , respectively. The standard deviation of the measured $Y_{1}$ from that obtained from a linear best fit of Eq. (11) is $2.8 \%$.

Equation (11) can be rearranged into a convenient form for the solution of the Reynolds number exponent (b) as:

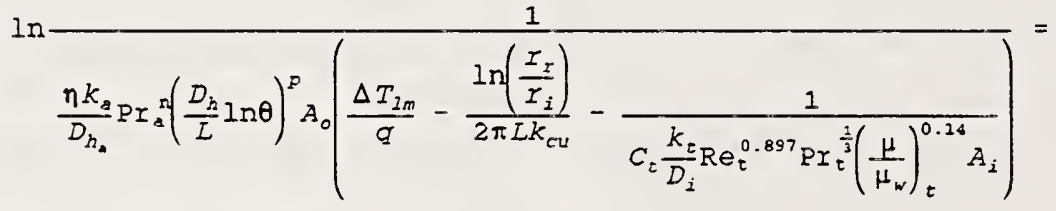

$$
\begin{aligned}
& b \ln R e_{\mathrm{a}}+\ln \left(C_{\theta}\right)
\end{aligned}
$$

The first term $\left(\mathrm{Y}_{2}\right)$ of Eq. (12) is plotted versus $\ln \left(\mathrm{Re}_{\mathrm{a}}\right)$ which is $\mathrm{X}_{2}$ in Figure 7 . The annulus Reynolds number exponent was obtained from the slope of a linear best fit of Eq. (12). The constant $C_{a}$ was obtained from the intercept of this fit. The $\mathrm{C}_{\mathrm{a}}$ from Eq. (12) must agree with that obtained from Eq. (11). The standard deviation of the measured $Y_{2}$ from that obtained from a linear best fit of Eq. (12) is $3.8 \%$. 
The additional unknown exponents $\mathrm{n}$ and $\mathrm{p}$ were solved iteratively. First, values for $\mathrm{n}$ and $\mathrm{p}$ were assumed. Then $C_{t}$ and $C_{a}$ were obtained from a linear regression of Eq. (11). The resulting $C_{t}$ was substituted into Eq. (12) to solve for an updated annulus-side Reynolds number exponent (b) and $\mathrm{C}_{\mathrm{a}}$. Iterations on Eqs. (11) and (12) were performed until successive values for $C_{t}$ and $C_{a}$ converged. An updated value for the annulus-side Prandtl number exponent (n) and the exponent $\mathrm{p}$ were obtained from a regression on the annulus-side Nusselt numbers. The annulus Nusselt numbers were solved by substituting the tube-side heat-transfer coefficient obtained from the correlation developed from the Wilson plot into the overall conductance equation. The procedure was repeated until all constants converged to a single value.

The $\mathrm{C}_{\mathrm{t}}$ from the Wilson plot was 0.0122 . The tube-side Nusselt number obtained from the Wilson Plot agreed with the Petukhov-Popov equation, on average, within $3.3 \%$.

The surface efficiency $(\eta)$ was approximated by assuming that the fin heat-transfer coefficient was constant and the fin cross section was uniformly rectangular. The fin cross sectional area and perimeter were estimated from length weighted average values of the tail and head of the fin of the spine shown in Figure 2. The average $\eta$ was 0.74 . The fin efficiency calculation procedure developed by Carranza (1993) for pyramid shaped spines was not used since it was felt that the fins in this study more closely resembled rectangles rather than pyramids.

\section{$\mathrm{Nu}_{\mathrm{a}}$ Correlations}

The following empirical Nusselt number correlation for the integral-spine-fin annulus was obtained from the Wilson plot:

$$
\mathrm{Nu}_{\mathrm{a}}=1.8 \mathrm{Re}_{\mathrm{a}}^{0.591} \operatorname{Pr}_{\mathrm{a}}^{0.518}\left(\frac{D_{h}}{L} \ln \frac{T_{w}-T_{i}}{T_{w}-T_{m}}\right)_{a}^{0.48}
$$


Equation 13 is recommended for Prandtl numbers from 4 to 22, and Reynolds numbers from 100 to 1400 where $\mathrm{Gr} / \mathrm{Re}^{2}<<1$. The uncertainty of Eq. (13) was estimated from a propagation of errors to be, on average, $17 \%$ of $\mathrm{Nu}_{\mathrm{a}}$.

The solution of Eq. (13) requires an iteration for the thermal developing correction. If an explicit solution is preferred, a version of Eq. (13) without the thermal developing correction is:

$$
\mathrm{Nu}_{\mathrm{a}}=0.142 \mathrm{Re}_{\mathrm{a}}^{0.508} \operatorname{Pr}_{\mathrm{a}}^{0.416}
$$

The uncertainty of Eq. (14) is the same as that of Eq. (13). However, a small $\mathrm{Nu}_{\mathrm{a}}$ uncertainty does not verify the form of the Nusselt number equation; it originates from small uncertainties in the calculation of $Y_{1}, X_{1}, Y_{2}$, and $X_{2}$. A good Wilson plot fit -- small $s_{Y 1}$ and $s_{Y 2}$-- suggests that the chosen form is correct for the correlated data set. If the genuine form was known, the correlation would predict all ranges of data to within its calculated uncertainty. Moreover, a correlation could have a small uncertainty and be unable to predict outside the data source range because it has an incorrect form. Therefore, the authors prefer Eq. (13) over Eq. (14) since it is expected that errors may result using Eq. (14) for heat exchangers that do not experience thermally developed flow similar to that experienced by our test section.

A comparison of the exponents in Eqs. (13) and (14) to exponents of other empirical correlations in the literature somewhat authenticates Eqs. (13) and (14). First, the Reynolds number exponent is between that obtained by Chen et al. (1946) for laminar flow (0.45) and that obtained by Davis (1943) for turbulent flow (0.8) within a smooth annulus. Even though the present annulus Reynolds numbers are laminar, the staggered fins presumably produce chaotic mixing which is more effective than laminar flow. This mixing is not quite as efficient as the random mixing of turbulent flow. Consequently, the Reynolds 
number exponent reflects an intermediate value between turbulent and laminar flow. Second, Chen et al. (1946) used $\left(D_{h} / L\right)^{0.4}$ to account for the thermally developing boundary layer. The power to which the $D_{h} / L$ term is raised in the Chen et al. (1946) correlation is close to the power used for the same term in Eq. (13).

The influence of the spines on the enhancement of the heat transfer can be investigated with the Chen et al. (1946) correlation which was developed for laminar flow within an annulus without fins:

$$
\mathrm{Nu}_{\hat{a}}=1.02 \operatorname{Re}_{a}^{0.45} \operatorname{Pr}_{a}^{\frac{1}{3}}\left(\frac{\mu}{\mu_{w}}\right)_{a}^{0.14}\left(\frac{D_{h}}{L}\right)^{0.4}\left(\frac{D_{0}}{D_{I}}\right)^{0.8} \operatorname{Gr}_{a}^{0.05}
$$

For example, if the spine-fin hydraulic diameter is used for $D_{h}$ along with the pre-finning pipe diameter $D_{p}$ for $D_{r}, E q$. (15) underpredicts the integral-spine-fin Nusselt number by an average of $26 \%$. This suggests that the heat transfer enhancement is due not only to the additional surface area, but also to the flow mixing that the fins provide. Consequently, good heat transfer practice dictates that the fins touch the outer wall. Otherwise, as shown by Knudsen and Katz (1950), laminar flow remains in unmixed ribbon-like stream lines in the annular space between transverse fins and the outer wall.

The magnitude of the fins enhancement can be better illustrated with a comparison of the fin and root heat transfer coefficients. The fin efficiency weighted heat-transfer coefficient for the fin $\left(\eta_{\mathrm{f}} \mathrm{h}_{\mathrm{f}}\right)$ normalized by that for the root surface $\left(h_{r}\right)$ is plotted versus the Prandtl number in Figure 8 . The $h_{r}$ was obtained from the Chen et al. (1946) correlation using the root diameter. The $h_{f}$ was obtained from substitution 
of $h_{r}$ and the measured spine fin heat-transfer coefficient into a sum of the individual heat-transfer coefficients weighted by surface area:

$$
h_{f}=\frac{\eta h_{a}-h_{I} \frac{A_{I}}{A_{0}}}{\frac{A_{f}}{A_{0}} \eta_{f}}
$$

The figure shows that the fin has anywhere from $10 \%$ to $50 \%$ higher heat transfer that the root surface. Presumably, the fin enhancement results from high heat transfer at the leading edge of the fins (performing like short plates) and the flow mixing produced by the staggered fins. The mixing enhancement becomes more pronounced at higher Pr since the fins are more effective than the root surface at converting momentum to thermal energy.

Extrapolation of Eq. (13) for spined annuli with different hydraulic diameters was done by including the same parameter $\left(\left(D_{0} / D_{h}\right)^{0.8}\right)$ that Chen et al. (1946) used to account for the effect of different smooth annuli geometries. The resulting equation is:

$$
\mathrm{Nu}_{\mathrm{a}}=0.439 \mathrm{Re}_{\mathrm{a}}^{0.591} \operatorname{Pr}_{\mathrm{a}}^{0.518}\left(\frac{D_{h}}{L} \ln \frac{T_{w}-T_{i}}{T_{w}-T_{m}}\right)_{a}^{0.48}\left(\frac{D_{0}}{D_{h}}\right)^{0.8}
$$

Equation (17) should not be used if the heat transfer is governed by natural or mixed convection. Moreover, the extension of Eq. (13) to other hydraulic diameters is only an intuitive guess; data for annulus spine-fin of various hydraulic diameters are required to verify or disprove it.

\section{CONCLUSIONS}

Empirical correlations for the laminar, single-phase heat transfer and friction characteristics of an integral- 
spine-fin pipe within an annulus have been presented. The heat-transfer coefficient was determined with a modified version of the Wilson Plot method. An additional term was included in the empirical correlation for the Nusselt number to account for the development of the thermal boundary layer. The exponential dependence of this term and the annulus-side Reynolds and Prandtl numbers were all determined via the modified Wilson plot. The single-phase, smooth tube-side correlation obtained from the Wilson plot agreed to within 3\% of the Petukhov-Popov equation. The spines enhance the heat transfer through additional surface area, fluid mixing and performing similar to short plates.

\section{ACKNOWLEDGEMENTS}

This work was jointly funded by NIST and the U.S. Department of Energy (project no. DE-AI0191CE23808) under Project Manager Esher Kweller. The authors would like to thank the following NIST personnel for their constructive criticism of the first draft of the manuscript: Dr. P. Domanski, Mr. R. Zarr, Dr. D. Ripple, and Mrs. J. Land. The authors would also like to express their appreciation to M. O. Kim for collecting a substantial amount of the test data. 


\section{REFERENCES}

Briggs, D. E., and Young, E. H., 1969, "Modified Wilson Plot Techniques for Obtaining Heat Transfer Correlations for Shell and Tube Heat Exchangers," Chem. Eng. Prngr. Symp. Ser., No. 92, Vol. 65, pp. 35-45.

Chen, C. Y., Hawkins, G. A., and Solberg, H. L., 1946, "Heat Transfer in Annuli," Trans. ASME, Feb., p. 99-106.

Carranza, R. G., 1993, "Spine Fin Efficiency of Spined Pipe Heat Exchangers," AICHE Symposium Series: Heat Transfer - Atlanta 1993, No. 295, Vol. 89, pp. 198-204.

Davis, E. S., 1943, "Heat Transfer and Pressure Drop in Annuli," ASME Trans., pp. 755-760.

Deissler, R. G., 1955, "Turbulent Heat Transfer and Friction in the Entrance Regions of Smooth Passages," ASME Trans., pp. 1221-1233.

Filonenko, G. K., 1954, Teploénergetika, No. 4.

Gnielinski, V., 1976, "New Equations for Heat and Mass Transfer in Turbulent Pipe and Channel Flow," Int. Chem. Engineering, Vol. 16, pp. 359-368.

Hobson, M. and Weber, J. H., 1954, "Spined Tubes in Exchangers: Heat Transfer Characteristics", Ind. Eng. Chem.: Engineering, Design, and Process Development, Vol. 46, No. 11, pp. 2290-2294. 
Holtzapple, M. T., Allen, A. L., and Lin, K., 1990, "Heat Transfer and Pressure Drop of Spined Pipe in Cross Flow-Part II: Heat Transfer Studies," ASHRAE Trans. pt. 2, paper \# 3393.

Holtzapple, M. T., and Carranza, R. G., 1990, "Heat Transfer and Pressure Drop of Spined Pipe in Cross Flow-Part I: Pressure Drop Studies," ASHRAE Trans. pt. 2, paper \# 3392.

Jakob, M., and Rawest, K. A., 1941, "Heat Transfer to a Fluid in Laminar Flow Through an Annular Space," AICE Trans., Vol. 37, pp. 619-648.

Knudsen, J. K., and Katz, D. L., 1950, "Heat Transfer and Pressure Drop in Annuli: Measurements on Plain and Transverse Fin Tubes Using Water," Chem. Eng. Progr., Vol. 46, pg. 490-500.

Kays, W. M. and Crawford, M. E., 1980, Convective Heat and Mass Transfer, McGraw Hill Book Co., 2nd ed., New York, pg. 109.

Mattingly, G. E., and Yeh, T. T., 1991, "Effects of Pipe Elbows and Tube Bundles on Selected Types of Flowmeters," Flow Meas. Instrum., Vol. 2, pp. 4-13.

Petukhov, B. S., and Popov, V. N., 1963, "Theoretical Calculation of Heat Exchange and Frictional Resistance in Turbulent Flow in Tubes of an incompressible Fluid with Variable Physical Properties," English Trans. High Temp., Vol. 1, No. 2, pp. 69-83.

Shah, R. K., 1990, "Assessment of Modified Wilson Plot Techniques for Obtaining Heat Exchanger Design Data," Heat Transfer 1990, Vol. 5, pp 51-56. 
Shah, R. K., 1985, "Compact Heat Exchangers," Handbook of Heat Transfer Applications, McGrawHill, N.Y., eds. W. M. Rohsenow, J. P. Hartnett, and E. N. Ganic, 2nd ed., Chapter 4, Part 3, pp. 174312.

Sieder, E. N., and Tate, G. E., 1936, "Heat Transfer and Pressure Drop of Liquids in Tubes, "Industrial and Engineering Chemistry, Vol. 28, pp. 1429-1435.

Vandersip, H. A., Heatron Inc., Private communications.

Webb, R. L., 1993, The Pennsylvania State University, Private communications.

Wilson, E. E., 1915, "A Basis for Rational Design of Heat Transfer Apparatus," Trans. ASME, Vol. 37, pp. $546-668$. 
Table 1 Average Estimated Percent Measurement Uncertainties

\begin{tabular}{|c|c|c|c|l|l|l|l|l|l|l||}
\hline \hline $\mathrm{C}_{\mathrm{a}}{ }^{-1}$ & $\mathrm{~b}$ & $\mathrm{Nu}_{\mathrm{a}}$ & $\mathrm{UA}$ & $\mathrm{q}_{\mathrm{a}}$ & $\mathrm{q}_{\mathrm{t}}$ & $\Delta \mathrm{T}_{\mathrm{lm}}$ & $\mathrm{Re}_{\mathrm{t}}$ & $\mathrm{Re}_{\mathrm{a}}$ & $\mathrm{Y}_{1}$ & $\mathrm{X}_{1}$ \\
\hline 4.2 & 4.3 & 16.6 & 8.1 & 1.8 & 0.7 & 8.0 & 0.6 & 2.2 & 9.9 & 4.9 \\
\hline
\end{tabular}


Table 2 Best-Fit for Annulus-Side Nusselt Number

\begin{tabular}{|c|c|c|c|c|c|c|c|c|}
\hline$(\mu / \mu \mathrm{w})^{0.14}$ & $\mathrm{Gr}^{0.05}$ & $\left(D_{h} \ln \theta / L\right)^{0.48}$ & $\% s_{Y 2}$ & $\% \mathrm{~s}_{\mathrm{Y} 1}$ & $\mathrm{C}_{\mathrm{a}}$ & b & $n$ & $C_{t}$ \\
\hline$x$ & $x$ & $x$ & 6.21 & 2.64 & 1.02 & 0.6 & 0.59 & 0.0129 \\
\hline $\mathrm{x}$ & $x$ & & 6.82 & 3.31 & 0.08 & 0.51 & 0.48 & 0.0134 \\
\hline \multirow[t]{2}{*}{$x$} & & & 7.04 & 4.69 & 0.17 & 0.49 & 0.40 & 0.0127 \\
\hline & $x$ & $x$ & 5.62 & 2.35 & 1.74 & 0.59 & 0.59 & 0.0129 \\
\hline \multirow[t]{3}{*}{$x$} & & $x$ & 4.11 & 3.12 & 1.74 & 0.60 & 0.51 & 0.0122 \\
\hline & & $x$ & 3.76 & 2.83 & 1.80 & 0.59 & 0.52 & 0.0122 \\
\hline & & & 4.13 & 3.37 & 0.14 & 0.51 & 0.42 & 0.0127 \\
\hline
\end{tabular}



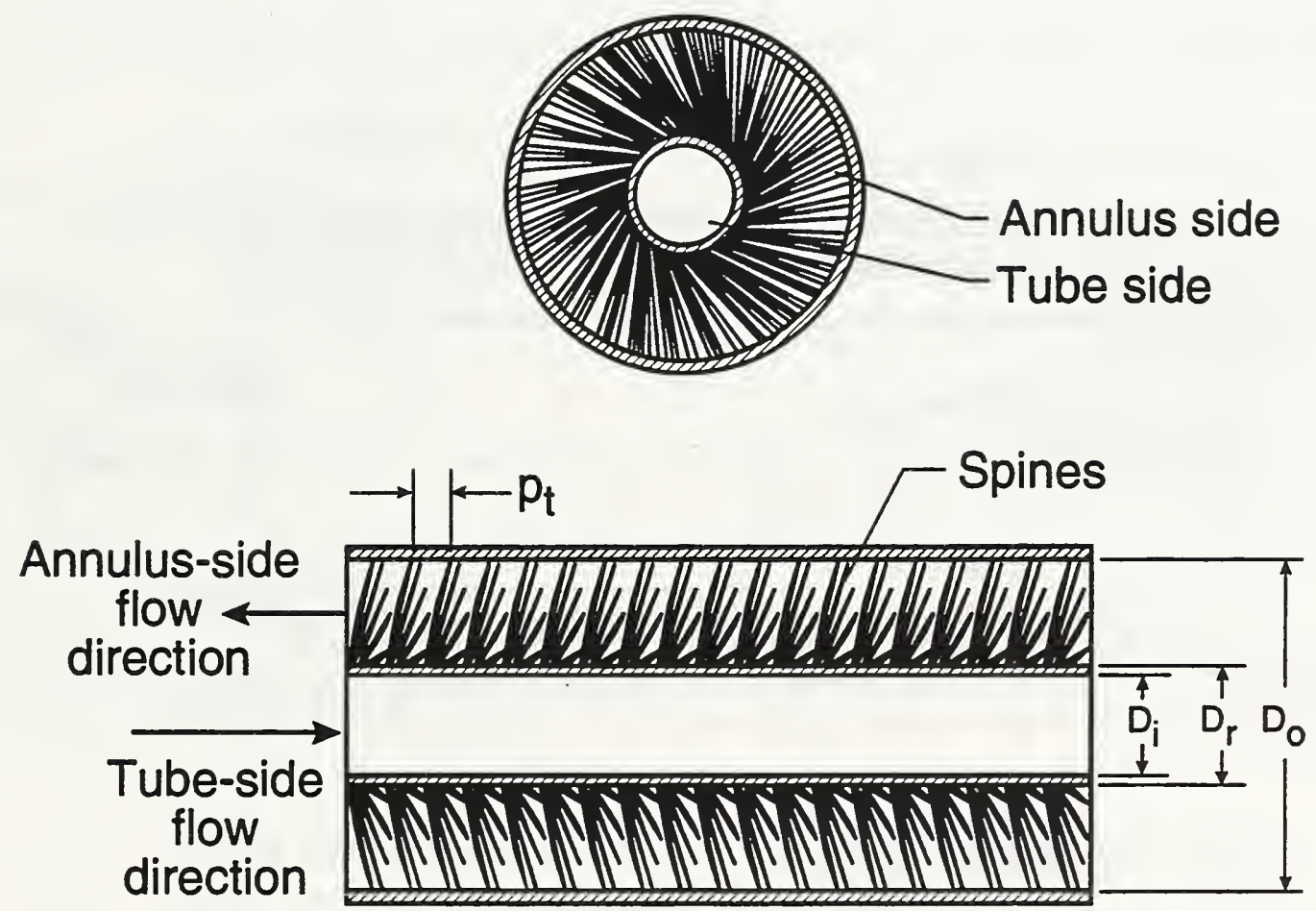

Figure $1 \quad$ Spine-fin surface and heat exchanger geometry 

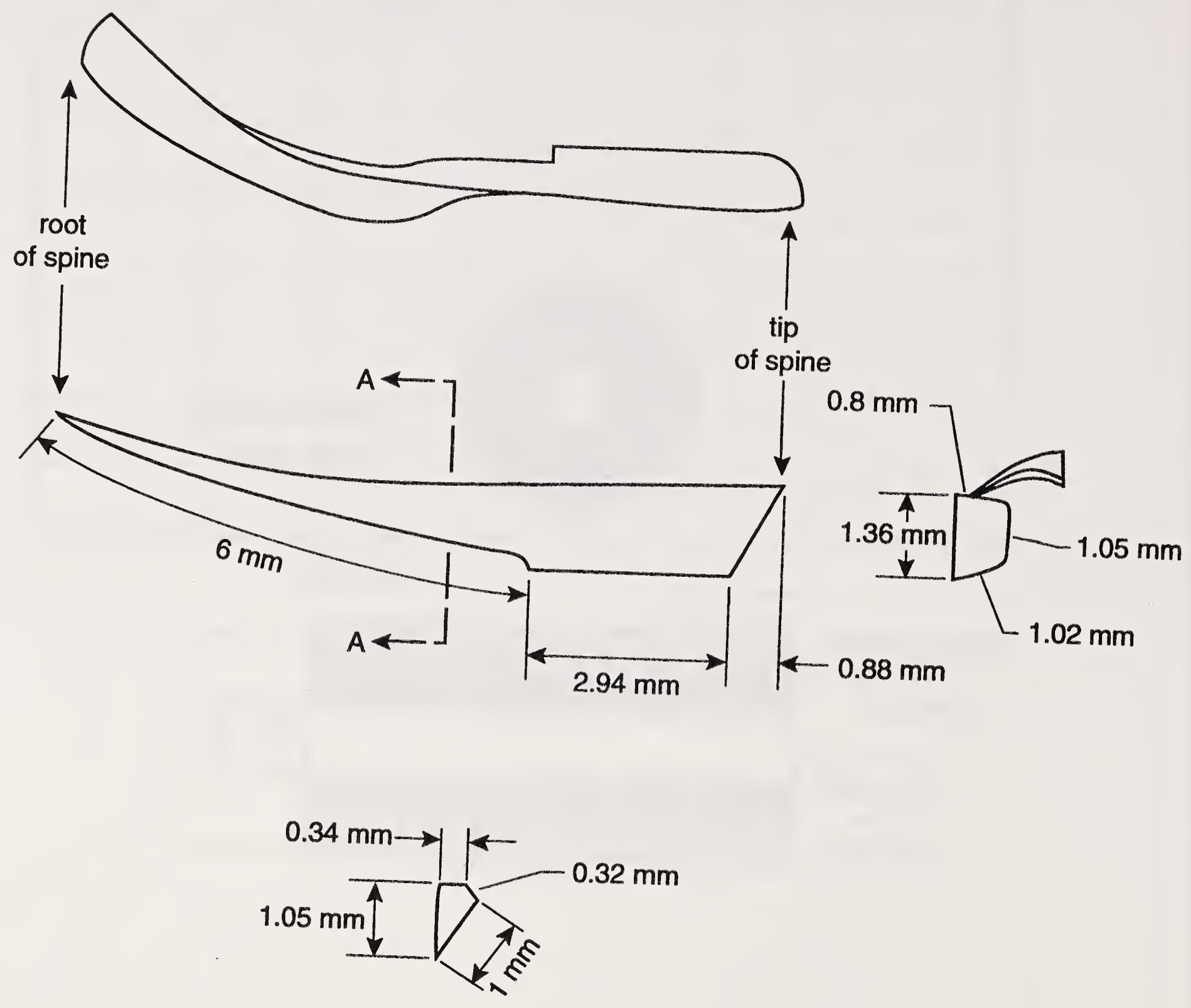

Section A-A

Figure 2 Schematic of spine 


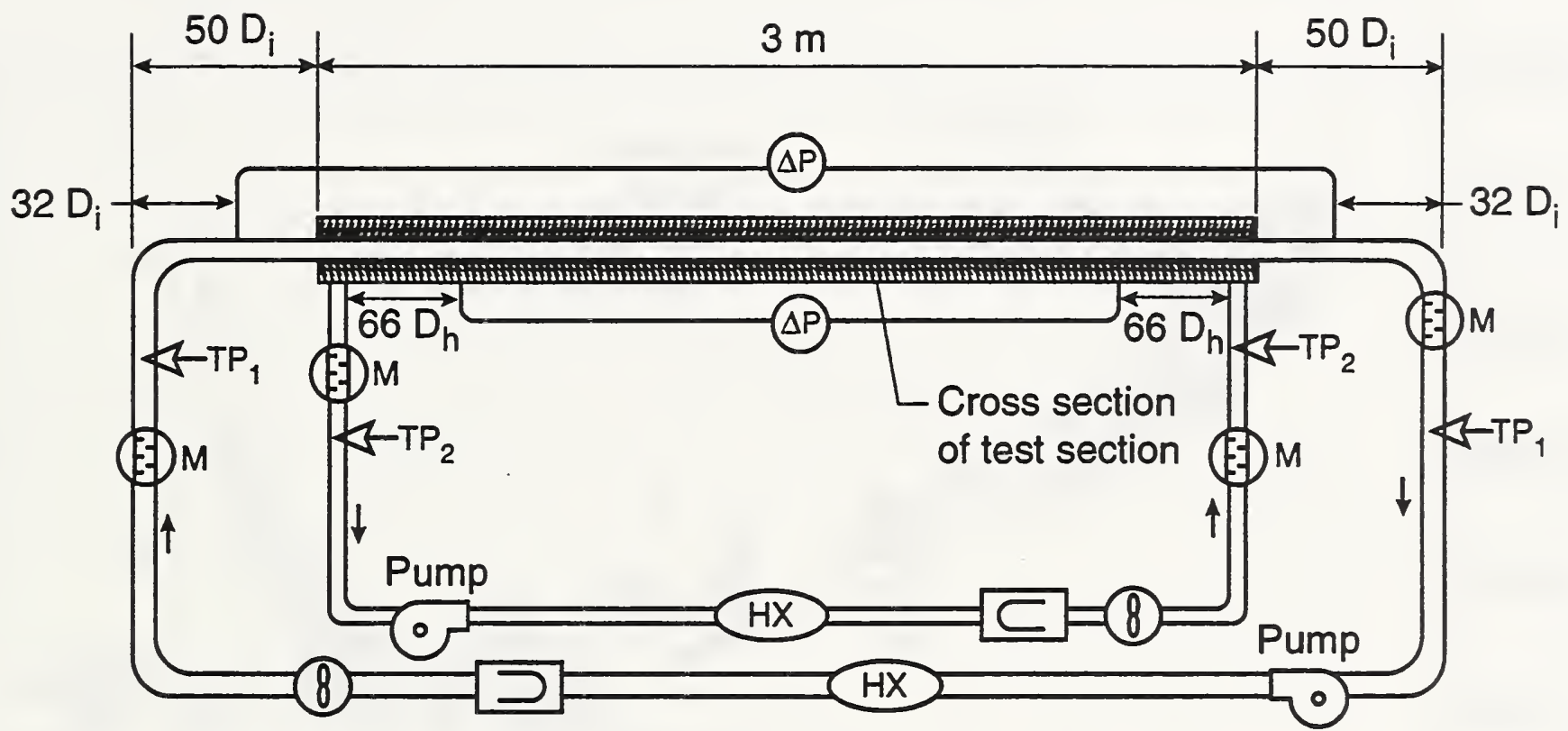

(E) M Fluid mixer

\&TP Thermopile

(AP) Differential pressure measurement

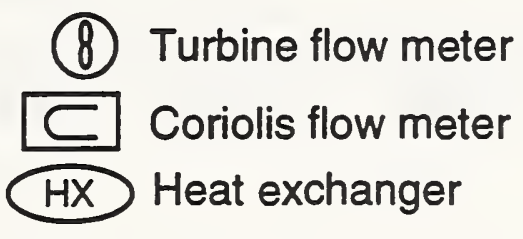

$\uparrow$ Flow direction

Figure $3 \quad$ Schematic of test rig 


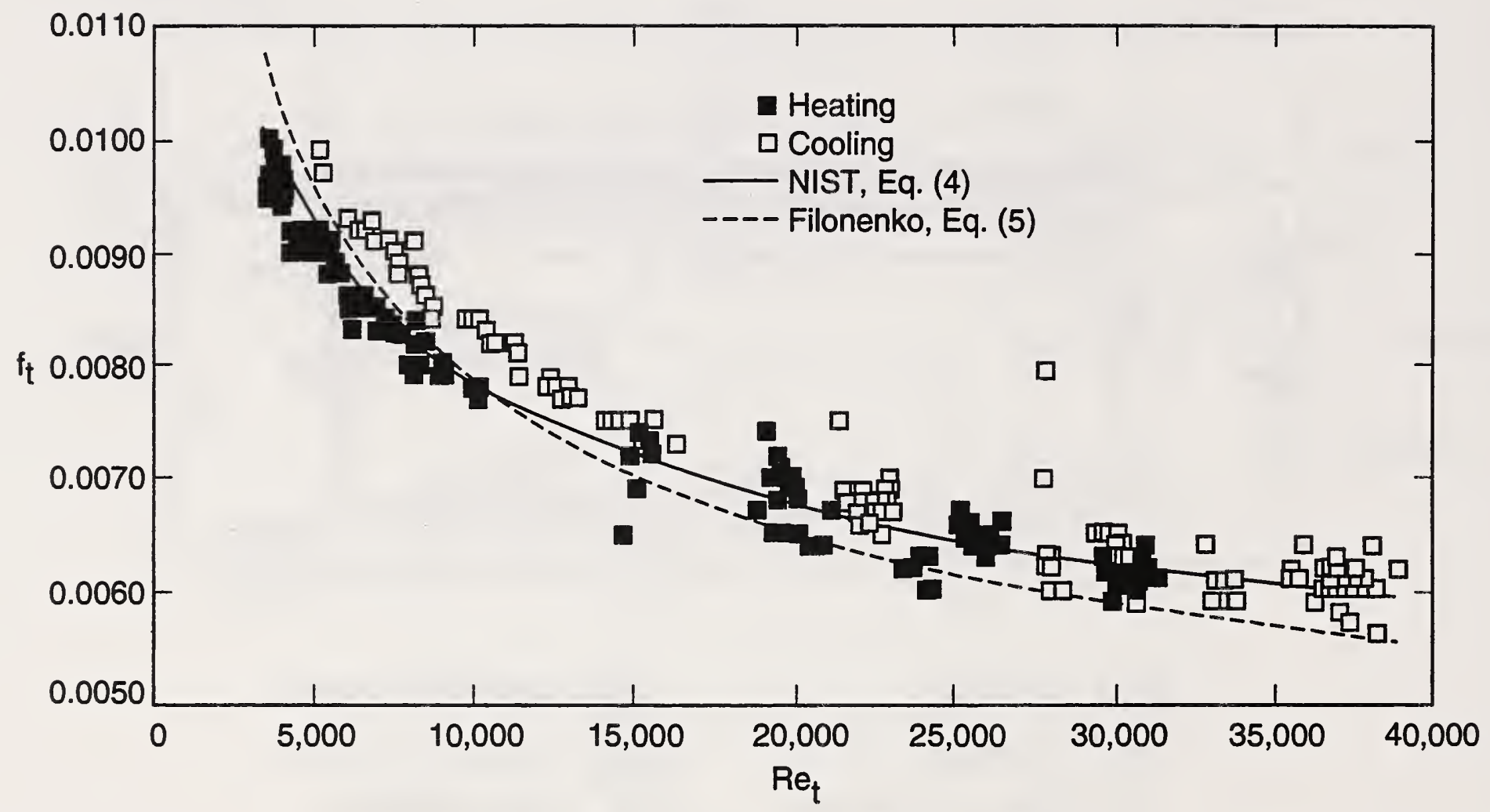

Figure 4 Measured smooth tube friction factor $\left(\mathrm{f}_{\mathrm{t}}\right)$ 


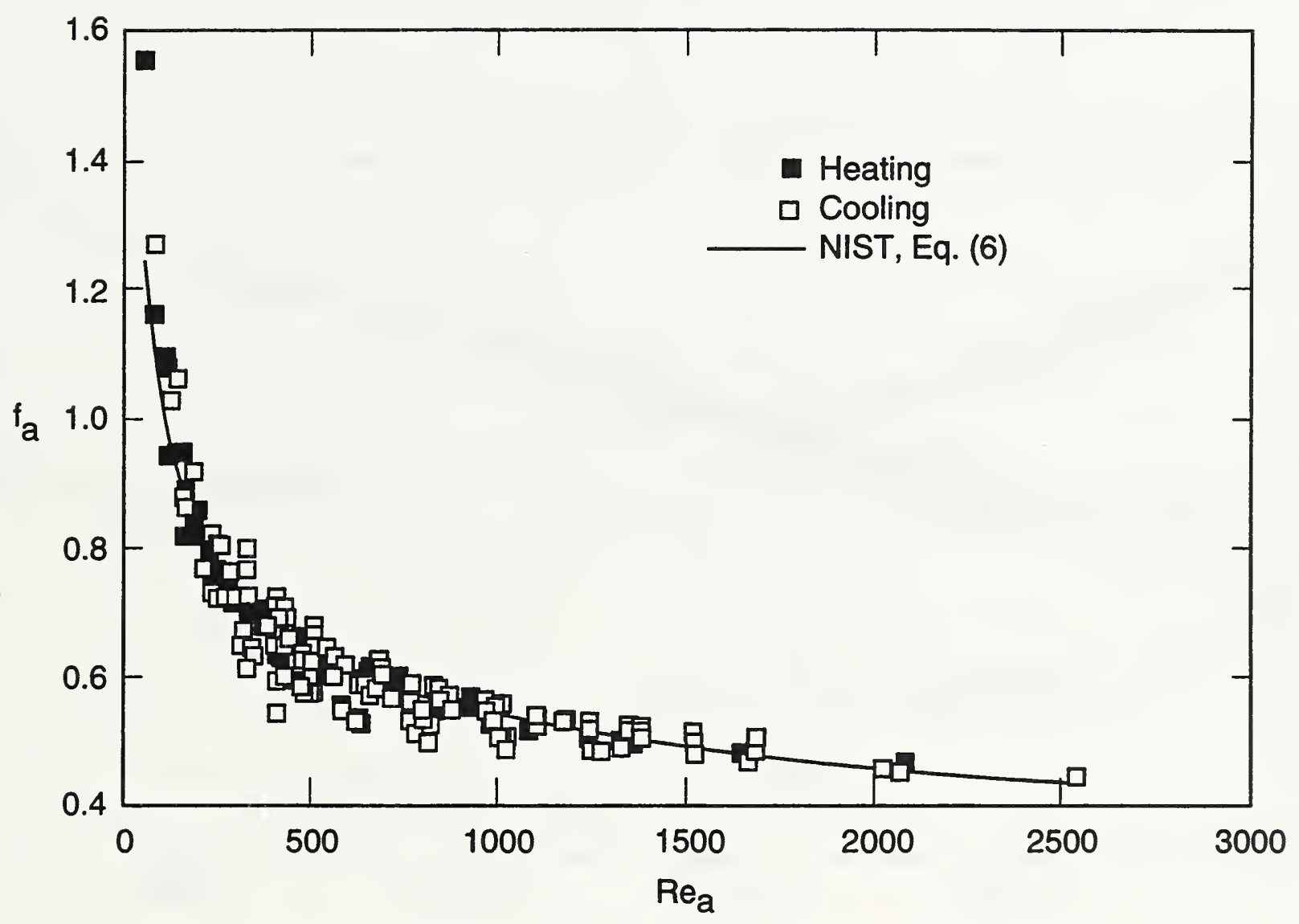

Figure 5 Measured integral-spine-fin annulus friction factor $\left(f_{a}\right)$ 


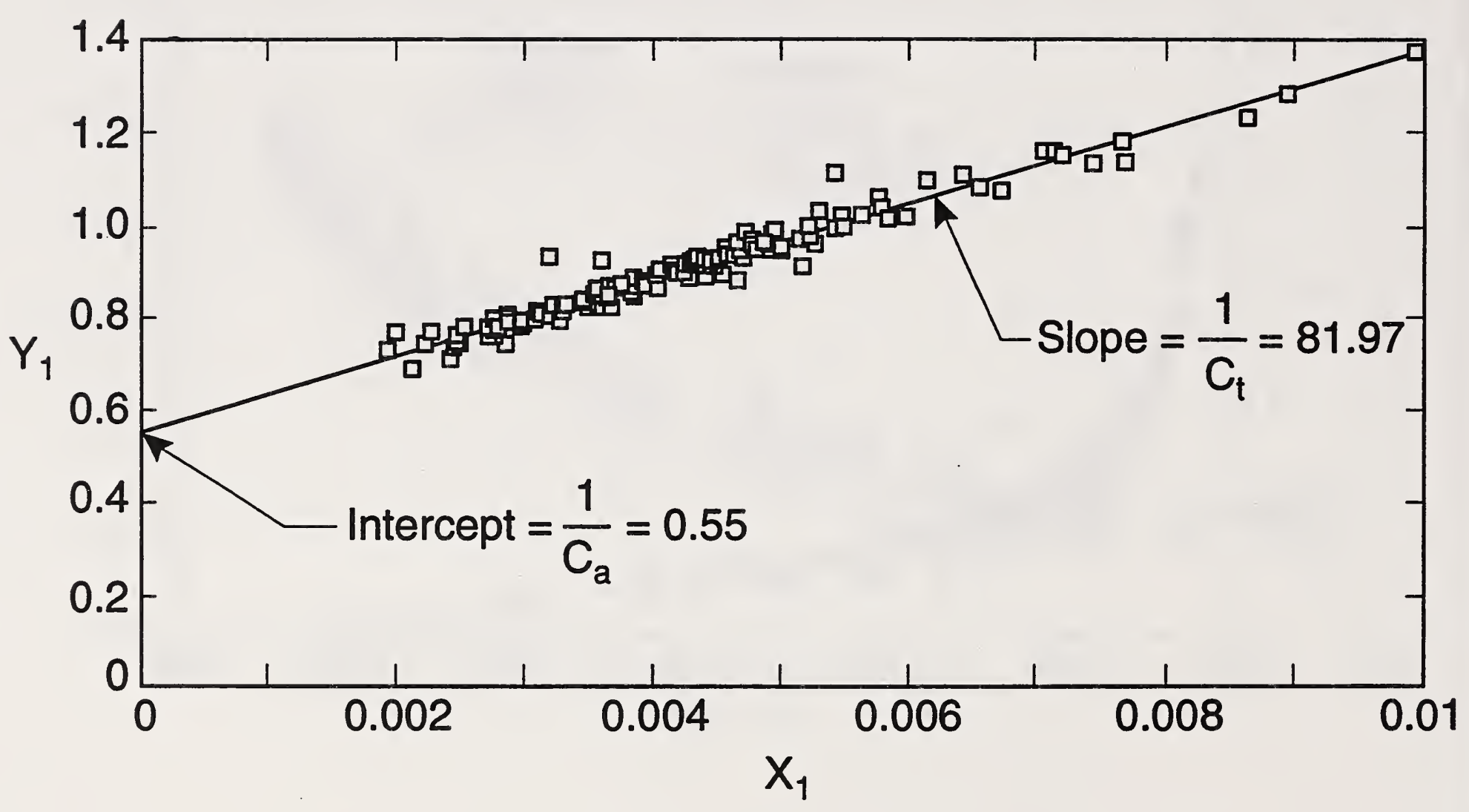

Figure 6 Wilson plot 1 


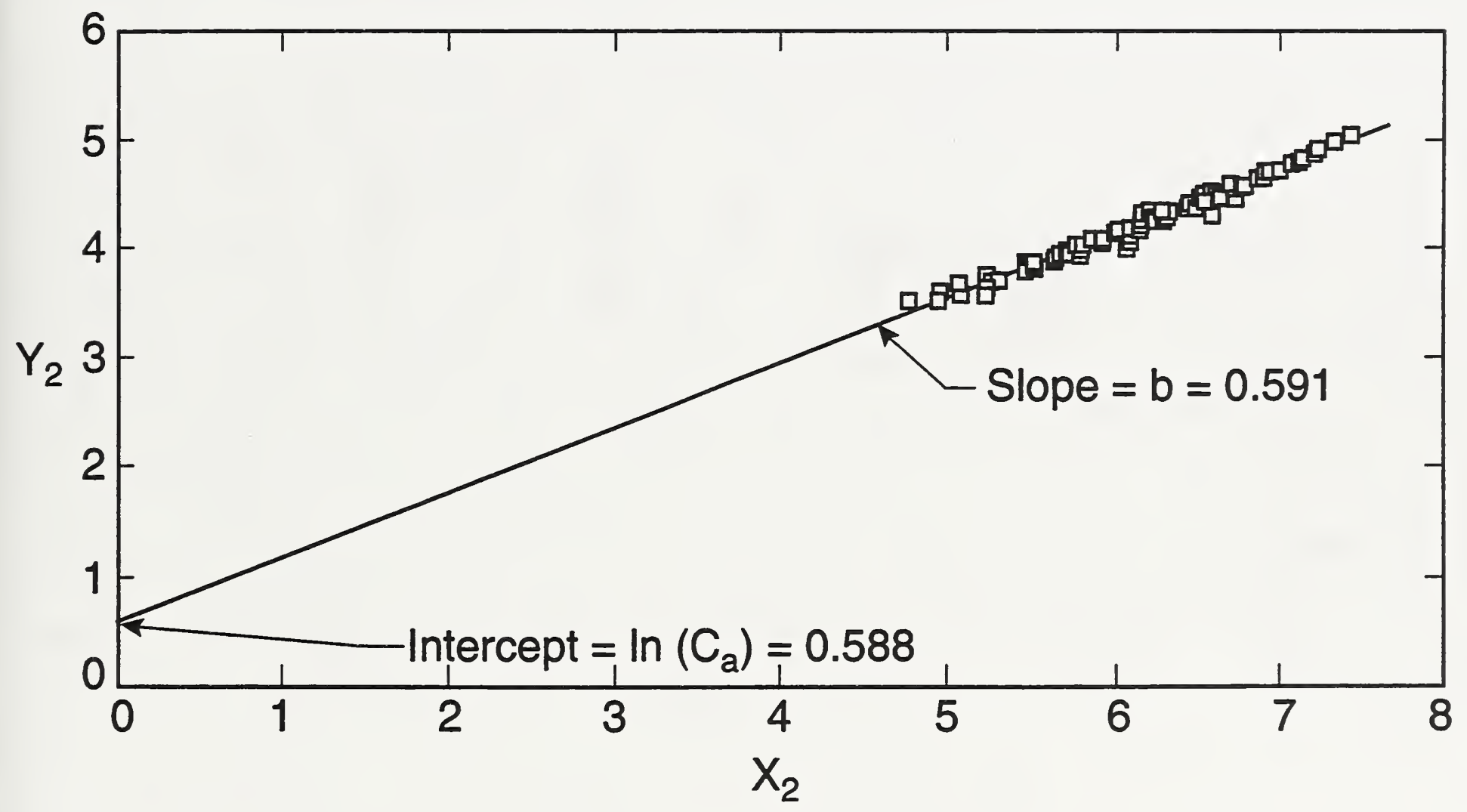

Figure $7 \quad$ Wilson plot 2 


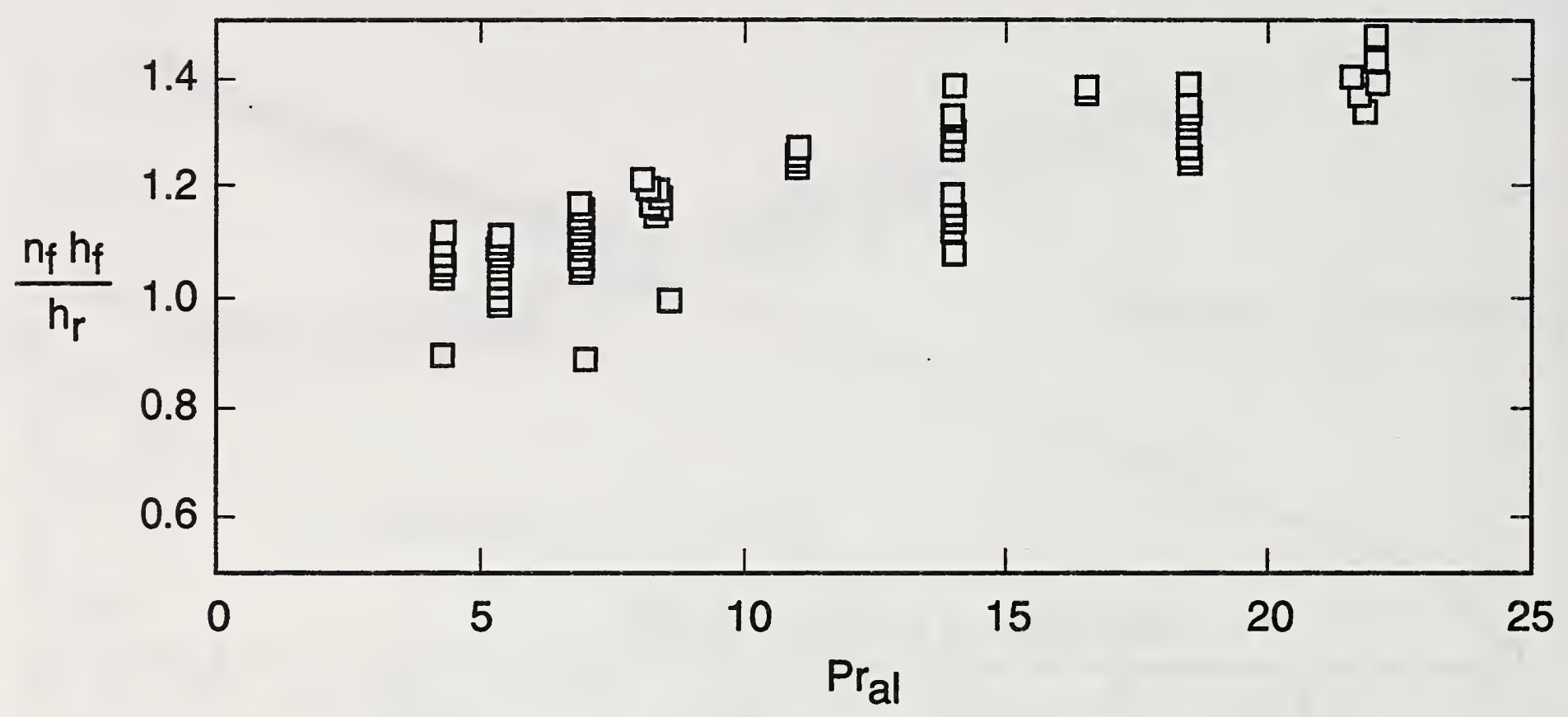

Figure 8 Comparison of the relative magnitudes of the fin heat-transfer coefficient to that for the root surface 

